\title{
La plaga de los vagabundos. Bandas salvajes por las carreteras alemanas
}

Daniel Guerin

(Exclusiva para El Imparcial, $\mathrm{n}^{\circ} 23.047,20$ de abril de 1933)

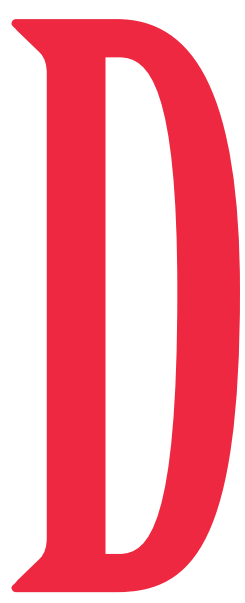

e urante mis peregrinaciones por las carreteras de Alemania me ha ocurrido encontrarme con grupos extraños que no se parecían a otro alguno. $\mathrm{Y}$ no estribaba su originalidad precisamente en el calzón corto, las piernas desnudas ni en el morral inverosímilmente pesado que caracterizan a los "wanderers" ordinarios. Como todos los jóvenes berlineses, éstos abandonan la ciudad el sábado por la tarde y regresan en la madrugada del lunes.

Pero estos otros grupos extraños a que me refiero traen unas caras sensuales, turbias, de golfos y un pergeño estarafalario: sobre la cabeza, copas de sombrero hongos viejos, negras o grises, sombreros de mujer con el ala levantada a "lo amazona", inocentes gorrillas proletarias adornadas en la visera con enormes "edelweiss".

¡Extraños bigardos! Los torsos, semidesnudos, les rebasan el maillot descotado; los brazos, llenos de tatuajes fantásticos, el cuello, ceñido por fin tajos de colores chillones; las orejas, adornadas con pinturas o inscripciones. Añadamos la muñequera de cuero, los zapatones de camino y obtendremos una mezcla de ruda virilidad y de afeminamiento casi imposible de describir.

Entre toda esta tropa, una mujer. Una sola mujer, sin adorno y sin disfraz, vestida como cualquier chica berlinesa. — ¿Qué clase de gente es ésta? — pregunto a un compañero de camino.

—Una "Wilde clique" — me réplica-. Una horda salvaje-, me dijo al oído mi compañero, con una mezcla de gravedad y de ironía.

De pronto me es dado descubrir, gracias a la casualidad de este encuentro, un mundo desconocido y lastimoso. Merced a esto, puedo abandonar las frágiles apariencias de la civilización. —¿Qué significan esas palabras sobre su calzón?
—Wild frei. Salvaje y libre. Es su divisa. Es su saludo.

$-¿$ Y en sus cinturones?

-Rauber... Bandido.

- ¿Y qué son estas "cliques"?

- Sociedades más o menos secretas de adolescentes descarriados, de jóvenes reñidos con la sociedad. $\mathrm{O}$, si lo prefieres, comunidades de bigardos que odian la comunidad...

$-¿$ Y su ideal? ¿Y sus fines?

-Vivir entre ellos, vagabundear, robar, destruir...

- ¿Y esa mujer?

-Es la "Cliquekuh". Vamos la vaca de la horda... Ese grandote que marcha a la cabeza del grupo y que lleva la insignia es, seguramente lo que ellos llaman "el toro de la clique". El "Cliquenbulle". Lo que en francés llamaríais al caid. La mujer es para él solo o para todos los individuos de la tribu. Según. Pero si te interesa esta cuestión conocerás en Berlín a una camarada que se ha consagrado en este oficio. La extravagante tropa había desaparecido hacía un rato en el horizonte; pero no de mi imaginación.

La joven de ojos claros y de gafas de concha que me presentó mi amigo se ha inclinado desde hace ya muchos meses sobre estos jóvenes golfos, con paciencia y casi con ternura. Ha conseguido ganar su confianza, vivir en su compañía, poseer sus secretos.

- ¿Por qué he hecho esto?-exclama. Porque es necesario conquistar esta desdichada juventud, víctima de la miseria. - ¿Cómo nacieron esas terribles "cliques"?

-Durante el caos de la guerra y de la postguerra. De 1916 a 1917 podían verse con frecuencia en los barrios extremos de las grandes ciudades grupos de jóvenes vagabundos, con frecuencia borrachos, vestidos con trajes de colores chillones. La gente, indignada, les llamaba "la plaga de los caminos". Estaban constituidos estos grupos por adolescentes, cuyos padres estaban en el frente y cuyas madres estaban en el taller. De su desarrollo material y moral nadie se ha ocupado.

-Después de la guerra-prosigue-primero, con la 


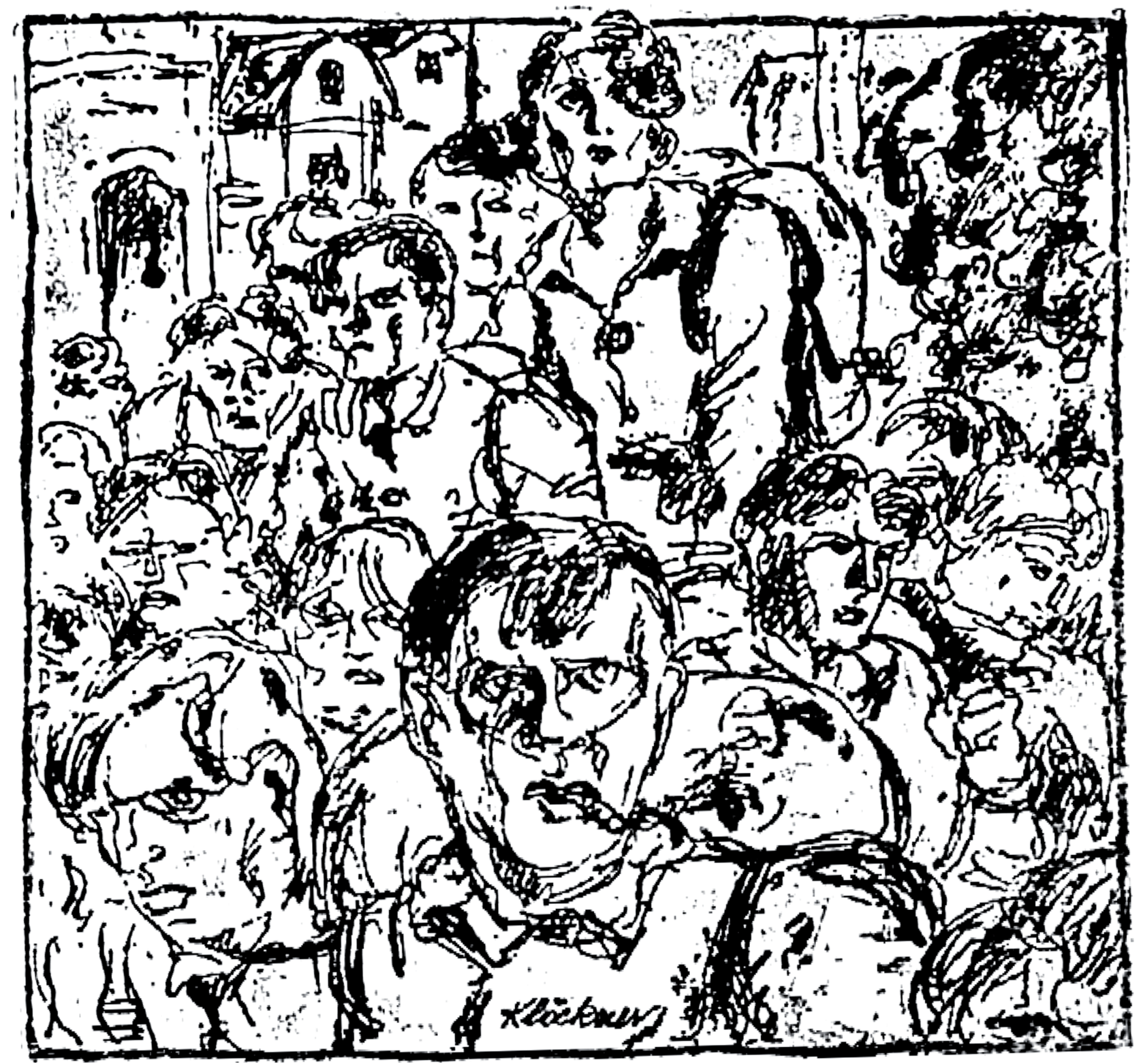

inflación, más tarde, con el paro, las hordas se desarrollaron de una manera alarmante. Piense usted que hay en Alemania 1.300.000 parados, entre los cuales cerca de un millón no percibe el socorro oficial. El caso corriente es éste: una familia proletaria de seis personas que vive en la misma habitación. Los padres, a fuerza de sacrificios, sostienen a sus hijos hasta que salen de la escuela, a los catorce años. Luego ya no pueden continuar los chicos en casa. Si el muchacho no encuentra trabajo, si no trae jornal, tiene que alquilar su cama...

-Entonces, ¿los echan a la calle?

-O a la "clique", que ofrece a estos desventurados la vida en común, la camaradería, el gusto del peligro y de la aventura. ¡Qué bien conoce esta mujer el calvario de estos pequeños! Entre los catorce y los diez y ocho años hay necesidad de amar, de expansionarse, de ser amado. Ya las privaciones sufridas durante la niñez - ¿no nacieron durante la terrible tormenta? - han repercutido bastante sobre su equilibrio físico y moral. Y la vida, encarnizadamente, les empuja fuera de la normalidad: les priva de trabajo. Para no caer víctimas de la melancolía, para no suicidarse, forman un mundo a su fantasía; un mundo que descansa sobre perceptos enteramente diferentes a los corrientes y admitidos; un mundo entregado al instinto sin limitación; un mundo de rencor contra la sociedad que les abandona al dolor y a la miseria.

"Wild Frei". Salvajes y libres. Rebeldes a la organización obrera y a toda autoridad. Revolucionados, pero no revolucionarios.

— ¿Todas las hordas son mixtas? - pregunto. 


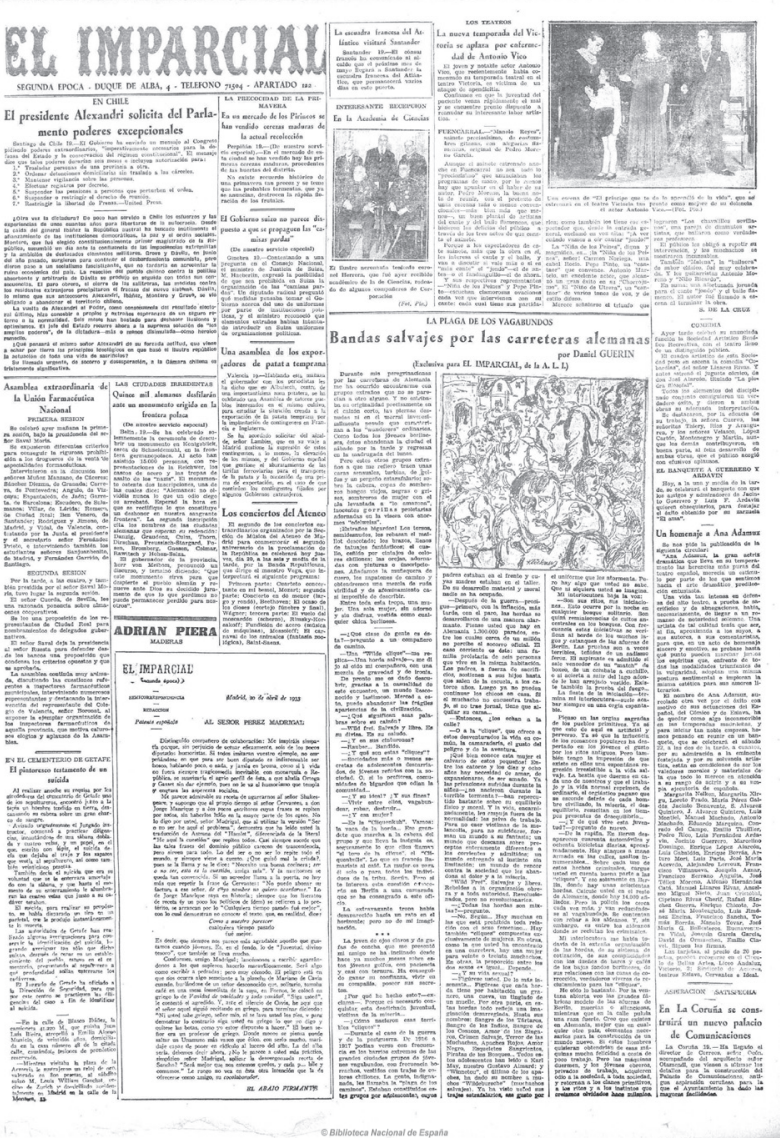

Imagen de la publicación original del artículo

—No. Según... Hay muchas en las que está prohibida toda relación con el sexo femenino... Hay también "cliques" compuestas exclusivamente de mujeres. En otras, como la que usted ha encontrado en una carretera, hay una mujer para veinte o treinta muchachos. En otras, la proporción entre los dos sexos es igual... Depende...

- ¿Y la vida sexual?

-Figúrese usted. De lo más insensata.... Figúrese que cada horda tiene por habitación un granero, una cueva, un tinglado de un muelle. Por otra parte, en estas hordas todo refleja una imaginación desarreglada. Hasta sus nombres: Sangre de los Tártaros, Sangre de los Indios, Sangre de los Cosacos, Amor de los Zingaros, Crimen Salvaje, Terror de las Muchachas, Apaches Rojos, Amor Negro, Esqueletos Sangrientos, Piratas de los Bosques... Todos estos adolescentes han leído a Karl May, nuestro Gustavo Aimard; y "Winnetou", el último de los apaches, ha dado su nombre a muchachos "Wildebursche" (muchachos salvajes). Ya ha visto usted sus trajes estrafalarios, ese gusto por el uniforme que les atormenta. Pero hay algo que usted no sabe. Que ni siquiera usted se imagina.

Mi interlocutora baja la voz:
-Son sus ritos, sus iniciaciones... Esto ocurre por la noche en cualquier bosque solitario. Son quizá reminiscencias de cultos ancestrales en los bosques. Con frecuencia estas iniciativas se verifican al borde de los muchos lagos y estanques de las afueras de Berlín. Las pruebas son a veces terribles, teñidas de un sadismo feroz. El aspirante es admitido si sale vencedor de un "match" de boxeo, de un combate a cuchillo, o si acierta a salir del lago adonde le han arrojado vestido. Existe también la prueba del fuego...

La fiesta de la iniciación — termina mi interlocutorasuele acabar siempre en una orgía espantable.

Pienso en las orgías sagradas de los pueblos primitivos. Ya sé que estos de aquí es artificial y perverso. Ya sé que la influencia de los romances populares ha despertado en los jóvenes el gusto por los ritos antiguos. Pero también tengo la impresión de que existe en ellos una espontánea regresión irresistible a la vida salvaje. La bestia que duerme en cada uno de nosotros y que el trabajo y la vida normal reprimen, de ordinario, el orgiástico pagano que se esconde detrás de cada hombre civilizado, la miseria, el desequilibrio, resucitan en los tiempos presentes de desequilibrio...

- ¿Y de qué vive esta juventud? - pregunto de nuevo.

Dela rapiña. En Berlín desaparecen cuarenta automóviles y ochenta bicicletas diarias, aproximadamente. Hay ataques a mano armada en las calles, asaltos innumerables... Sobre cada uno de estos hechos criminales, cargue usted en cuenta buena parte a las "cliques". Y eso solamente en Berlín, donde hay unas seiscientas hordas. Calcule usted en el resto de Alemania, donde hay 14.000 afilados. Pero la policía nos cerca cada vez más, y van reduciéndose la vagabundaje. Se contentan con robar a los aldeanos. Y, sin embargo, es entre los aldeanos donde se reclutan los criminales.

Mi interlocutora me habla todavía de la extraña organización de las hordas, de su sistema de cotización, de sus complicidades con los dueños de bares y cafés de los bajos fondos berlineses, de sus relaciones con las casas de corrección, verdaderos viveros de reclutamiento para las "cliques".

He oído lo bastante. Por la ventana abierta veo las grandes fábricas modelo de las afueras de Berlín, muertas o silenciosas, mientras que en la calle pulula una raza fuerte. Creo que existen en Alemania, mejor que en cualquier otro país, elementos necesarios para la construcción de un mundo nuevo. Si estos hombres quisieran obtendrían a estas máquinas mucha felicidad a costa de poco trabajo. Pero las máquinas duermen, y los jóvenes obreros privados de trabajo, adquieren odio a la sociedad, a toda sociedad, y retornan a los clanes primitivos, a los ritos y a los instintos que creíamos olvidados hace milenios. 

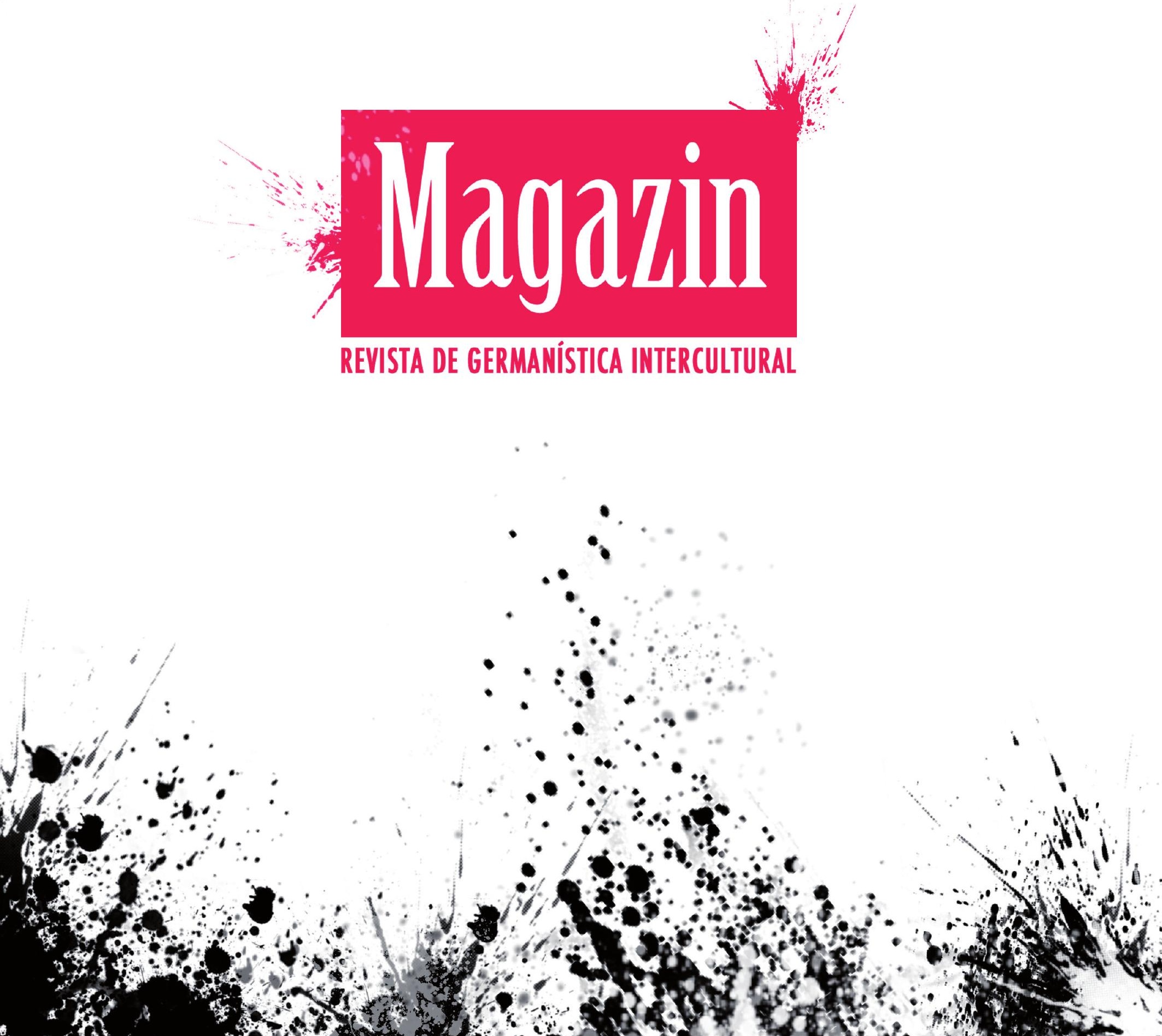